\title{
An ethical toolkit for food companies: reflections on its use
}

\author{
Marian Deblonde \\ Department Environment, Technology \& Technology Management \\ Research Centre for Technology, Energy and Environment - STEM \\ Stadscampus \\ Prinsstraat 13 \\ 2000 Antwerp \\ Belgium \\ T +32 (0)3 22049 07; F +32 (0)3 2204901 \\ www.ua.ac.be/STEM
}

\begin{abstract}
Nowadays many debates are going on that relate to the agricultural and food sector. It looks as if present technological and organizational developments within the agricultural and food sector are badly geared to societal needs and expectations. In this article we briefly present a toolkit for moral communication within the food chain. This toolkit is developed as part of a European research project. Next, we discuss what such a toolkit can bring about, given the characteristics of the present day agricultural and food sector and its wider context. We defend that the toolkit can be seen as one of the mechanisms that can help enterprises in the agricultural and food sector to be accountable. It should, however, be complemented with other mechanisms, first, to empower the wider public and, second, to stimulate a dialogue, on a more equal footing, between public authorities, citizens and economic actors.
\end{abstract}

KEYWORDS. Food sector, moral communication, ethical toolkit, CSR (developed form), empowerment, equal dialogue

\section{Introduction}

Nowadays many debates are going on that relate to the agricultural and food sector. Consider topics such as actual and possible functions of the countryside, the pros and cons of GM crops and food, problems with food safety, societal desirability of multifunctional food, the responsibility and accountability of the food industry with regard to obesity, societal concerns regarding animal welfare, lack of food security for a growing number of people, and so on. It looks as if present technological and organizational developments within the agricultural and food sector are badly geared to societal needs and expectations. 
In this article we will focus on a toolkit developed to facilitate ethical decision-making by economic actors in the food chain. ${ }^{1}$ Our main question is: what can such an ethical toolkit bring about and what are its limitations, given the characteristics of the present day agricultural and food sector and its wider context.

In the next section, we will present characteristics of the present day agricultural and food sector and of its wider context. Then, we will elaborate on the topic of moral communication. In the fourth section, we will sketch the toolkit we developed: its general aim and its structure. In section five, we will consider the implications of these characteristics for the use and limits of our toolkit. We will, finally, formulate some suggestions that can help to realize the underlying intention of the project, namely a better tuning between developments in the agricultural and food sector on the one hand and societal desires and expectations on the other.

\section{The Actual context}

The food system is undergoing a revolution transforming how food is produced, who produces it and where, how it is processed and distributed, how it is cooked and where we eat it (MacMillan 2005, 5). The drivers of this revolution range from deliberate government policies, and specific challenges in health, the environment and the economy, to much broader cultural shifts.

\subsection{Changing technologies}

During the last decades the main objective of agricultural and food policies in Western countries has been to provide enough and safe food (Apotheker 2000, 9; Staman \& Brom 2000, 207). This objective has been supported by rapid and effective technological innovations. Nowadays tensions exist between the striving for more economic efficiency in food production on the one hand and satisfying concerns about food quality and sustainability on the other. At the same time a mental gap has grown between actual food production methods and consumers' ideas of them. Many consumers have a romantic picture of food production that is often re-enforced by food marketing. When - mostly in situations of food crises - they are confronted with the reality of food production, they feel alienated. The technological and scientific approach to food seems out of touch with the role of food in people's life world. (Beekman 2000, Brom 2000)

\subsection{A changing economic structure}

In the food sector both co-operation and market competition have their place (Brom et al 2004a, 52-53). On the one hand, different parties work (sometimes) together, use common standards and aim at common goals (e.g. food safety). On the other hand, various companies operate as economic rivals. In this context, norms and values can play ambiguous roles. They can be a sign both of moral conviction and of strategic cleverness. A good insight in the market positions of various companies and in the distribution of economic power between producers and consumers is helpful to evaluate the possibilities and limits of tools developed for moral communication within the food chain.

\footnotetext{
1 This paper presents results from the project Ethical Bio-TA Tools, as funded by the European Commission, under FP5, Quality of Life Programme. The CoMoRe kit is a substantiated composition of models to stimulate moral communication. The authors are looking for occasions to test this kit in a variety of circumstances within the food sector.
} 
One trend in power emerges as particularly significant: the trend towards corporate concentration in the food supply chain. At most stages of processing and distribution the number of companies involved is diminishing and the market share of the largest players is growing.

Available analyses regarding the evolution of power relations within the agricultural and food sector, with respect to European, Nord-American and developing countries, arrive at uniform conclusions ${ }^{2}$. They all observe three major changes that are occurring simultaneously in the economic structure of the food and agricultural system around the world: horizontal integration, vertical integration, and global dominance (IFAP 2004). Horizontal integration refers to the increased market concentration and control by a few firms at any stage of the food system, from the production of seed through the retailing of the final product. Vertical integration is the process in which one, or several, companies acquire a significant amount of control over a series of linked stages in the food and agricultural system. Global dominance occurs when a very limited number of transnational corporations control the food system through vertical and horizontal integration in a host of countries around the world. On the agri-business side, three large clusters of transnational companies - Cargill/Monsanto, Novartis/ADM/IBP, and ConAgra - dominate the sector (IFAP 2002). These clusters link up biotechnology companies, grain trading and processing companies, and meat production and processing companies. Three large global companies - Nestlé, Unilever, and Philip Morris dominate the food-processing sector. At the food-retailing end, four companies dominate global markets - Tesco (UK), Ahold (Netherlands), Carrefour (France), and Wal-Mart (USA) ${ }^{3}$. The analyses also show that while industrial concentration is occurring in all sectors of the agri-food chain, it is most prevalent in retailing (IFAP 2004, MacMillan 2005).

\subsection{Changing governance}

The changing of the structure has its influence on the way agriculture and food are governed. The UK Food Ethics Council (FEC) identifies three trends in governing (MacMillan, 2005) ${ }^{4}$.

The first trend named is the 'hollowing out' of the state, i.e. the shift of powers that are traditionally associated with national governments upwards by globalization and downwards by regionalization. Hegrenes and Borgen (2005) confirm this conclusion. According to them, the agreement on the European Economic Area (EEA) and the GATT/WTO agreement mean that restrictions are imposed on national support for agriculture and on import tariffs. In addition, there is a globalization of standards and reduced technical barriers to trade. The increasing globalization of the agri-food sector implies that national producers to a greater extent face foreign competitors. National regulations are increasingly harmonized. Accordingly, both producers and traders must take international standards into account.

\footnotetext{
2 Hegrenes \& Borgen 2005, IFAP 2002, IFAP 2004, Jacobsen et al. 2003, Rapeepun, Coleman \& Chiasson 2002, McMichael 2000, MacMillan 2005

3 According to Lang (2003, p.10, quoting CAP Gemini/Ernst \& Young 2002), the Top 10 Global Food Retailers consists of Wal-Mart (USA), Carrefour (EU), Ahold (EU), Kroger (USA), Metro (EU), Albertson's (USA), Kmart (USA), Rewe (EU), Tesco (EU) and Aldi (EU).

${ }^{4}$ In May and July 2005, the UK Food Ethics Council organised a series of three workshops. The workshops were intended to help participants understand and respond to major shifts in power that they deem to take place within the food system.
} 
The second trend consists of increasing regulation by the private sector. It is, for instance, increasingly the quality and safety standards set by retailers and other companies, rather than those set by governments, which matter most to producers and consumers. Retailers lead this standard setting and often neither producers nor consumers are involved in establishing good farming practices or in defining food conditions (IFAP 2002).

The third trend mentioned by FEC is an upsurge of civil society activity around food and agriculture. This latter trend refers, in other terms, to endeavors from within civil society to increase their share in the governance of the food and agricultural sector.

\subsection{Concerns}

Corporate concentration raises a number of concerns. In some sectors it has created oligopolies, in which a small number of companies sell a large proportion of products or services, giving them much greater power to raise prices than they would have if there was more competition (MacMillan 2005, 5). Major oligopsonies are also emerging, in which a small number of companies account for a large proportion of demand, allowing them to force down purchase prices. The large size of companies means that regulatory structures designed for smaller firms are rendered less effective. The international operations of these large companies mean that national-scale regulatory structures, for example competition rules, cannot govern them in the public interest. The economic power of these companies gives them considerable political influence, enabling them to capture regulatory bodies regionally, nationally and internationally. Trade liberalization has contributed to corporate concentration and the political clout of large companies enables them to promote further liberalization through such forums as the World Trade Organization (WTO). As a result of these mutually reinforcing processes, food security is coming to rely increasingly on international trade and on individual purchasing power, and this implies a risk for augmenting the vulnerability of food-insecure countries. (checken bij Ronald)

Several other analysts express their concern that some trends in governance are contrary to the public interest, unjust or unsustainable. As examples of such unjust or unsustainable consequences of these trends are mentioned: cheap food policies based on externalization of costs, low/squeezed earnings of primary commodity producers in developing (and industrialized) countries, the impact of price signals of 'unhealthy' vs. 'healthy' food on social marketing initiatives and health education, the civic/amenity implications of location/siting of shops (Lang 2003), sharp decline in the number of family farms and other independently owned businesses (IFAP 2004), growing gap between producer and retail prices, accelerating transfer of benefits from countries and regions that produce to those that consume, proliferating high food and feed standards in developed countries or private certification schemes as non-tariff barriers for developing countries (Jacobsen et al. 2003).

Lang suggests, moreover, that some developments such as growing water and oil scarcity might prompt dramatic change in shaping who will exercise power within the food system in coming years. He is worried that the present explosion of futures research that is intended to help decision-makers think strategically will exacerbate the current misdistribution of power, because these research projects are being carried out almost exclusively in the interests of those up the food chain, not in the interests of those below. 


\subsection{Food chain values}

It is widely acknowledged that, in order to bridge the gap between the producers and consumers of food and to respond to problems of mutual distrust, the food sector has to open up (Brom et al. 2004a, 44). Transparency and traceability are keywords in the food sector at the moment. Transparency, however, is in itself not enough. It is clear a) that just showing what you do in itself does not solve the problem, and b) that you cannot show everything to everybody. The same holds true for traceability. Which properties of food production should be traceable: origin, production method, environmental consequences of the production, and/or labor circumstances? Transparency and traceability presuppose clarity about the importance of what has to be shown and what has to be traceable. Transparency and traceability are needed to be clear about the values involved in food production. They are, consequently, a precondition for moral communication, i.e. for the investigation of, deliberation about and mutual attuning of the different value systems of the various actors in the food chain.

From previous research experiences we learned that the following values could summarize the normative base of concerns within the food sector: food security, food safety, food quality, food sovereignty, human welfare, animal welfare, ecological sustainability, transparency and traceability. (Of course, each of these values is a comprehensive concept which has to specified by several more concrete values.)

Food security regards the question whether we can produce enough food for a growing world population and whether the available food is fairly distributed. Food safety is not the same as food quality ${ }^{5}$. Food safety is characterized by the fitness for consumption of food products, and protection of consumers against food-borne health risks. These include microbiological risks (bacteria, viruses), toxicological risks (chemical agents - organic agents and metals like cadmium -, toxins), nutritional risks (allergens, nutritional imbalances), and physical contamination risks. Thus, food safety depends upon good farming practices, for example on the use of pesticides and veterinary medicines and on the control of hazards and contaminants. More broadly, food safety is an obligation to consumers by the different actors in the agro-food chain: farmers, processors, and distributors. Governments must assure food safety through the development, setting and administering of food safety legislation and regulations. Food quality is a complex notion made up of several different components including nutritional composition, visual appearance and taste. Food quality can also be related to the special characteristics of a product as a result of regional culture, or special efforts by farmers in their production practices. Producer quality assurance programmes, or certification schemes for the whole product chain that guarantee quality from the seed to the table, can control these. Food sovereignty is about whether people (of local communities, regions, countries) have the right and opportunity to produce their own food.

Human welfare focuses on labor conditions of workers in the food chain and on fair distribution of value added in the various stages of the food chain. Animal welfare regards the living conditions of animals and a justified use of animals for human purposes. Ecological sustainability aims at a justified use and transformation of our natural

\footnotetext{
5 Food safety and quality. Policy Statement adopted at the 35th World Farmers' Congress of the IFAP, Cairo, Egypt, 2002, www.ifap.org, consulted on 06/09/2005
} 
environment in a way that does not compromise the living conditions of future generations.

Transparency is about accessibility of information regarding the construction and organization of food chains, production processes, norms and standards used, origin of products, and so on. Traceability regards the possibility to trace back the different sources of food products in the (increasingly complex) food chain.

\subsection{Accountability}

Evaluating trends in the food sector is not a univocal enterprise. Good governance for one group may be bad governance for another. Therefore, efforts to evaluate governance might best focus on processes, rather than outcomes. The U.K Food Ethics Council makes use of the concept of accountability to give expression to this procedural perspective (MacMillan 2005). Accountability, in this context, refers to all sorts of mechanisms that ensure that organizations exercising power fulfill their responsibilities and can be held to account by the groups they affect. Hence, it does not simply refer to liability or auditing processes. The key issue is, moreover, perhaps less by which mechanisms organizations are accountable but to whom they are accountable. Moral responsibilities of companies and public bodies extend beyond the shareholders or immediate stakeholders to whom they are made formally responsible. Therefore, these organizations ought to involve their wider constituency, namely the wider public and small-scale producers. (Why? Give some reasons.)

\section{Moral communication}

In order to be accountable with regard to the concerns and values relevant in the food chain, food companies need to engage in a moral communication with society. Before we present our toolbox, it might be helpful to elaborate the concept of moral communication first. Moral communication implies mutual exchange and understanding of each other's moral position (Brom et al., 2004a). It does not only regard expression of moral beliefs, principles, values and norms, but also their explanation and justification. Moral communication, thus, entails critical scrutiny of each other's values. The concept of moral communication has been elaborated in the discussion about education with regard to values and morals in a pluralistic society. One of the influential authors in this field is Van der Ven. In his book on the Formation of the Moral Self he defines $(1998,31)$ "moral communication as the ongoing process of moral exchange and understanding in the search of truth." He elaborates on the three keywords of this definition: moral exchange, understanding and truth as follows:

- 'Moral exchange means mutually expressing moral beliefs, principles, values, and norms, while also seeking to clarify, explain, and justify them.' From this we learn that moral communication does not only involve expressing, for example, that we think that animal welfare is an important value in our livestock production, but also giving reasons why we think so.

- 'Moral understanding is the adopting of another's perspective and heeding another's clarifications, explanations, and justifications. It involves adopting, at least temporarily, and taking into account the individual and social history out of which these emerge.' In moral communication, if someone expresses, e.g., doubts about the 
importance of a certain environment-friendly production system, we would need to understand the background from which this view is articulated.

- 'This moral exchange and understanding is part of the search for truth, the search for what is good and just so that one may act with wisdom in all of life's situations.' An easy example would be the use of slavery in agricultural practice (volgens één reviewer een te gemakkelijk voorbeeld, dat bovendien te ver van ons af staat). When we agree that one is justified in calling certain working circumstances slavery, we not only agree that these situations are unacceptable but also think that we agree rightly so.

It is important to distinguish between two different levels of moral communication: a first order moral communication that is characterized by plausibility, and a second order communication that is characterized by justification.

In first order communication the 'perceptions, experiences, images, metaphors, symbols, stories, convictions, principles, values, and norms that are dealt with and exchanged (...) are taken as self-evident, reasonable, understandable. They need not to be discussed or proved' (Van der Ven 1999, 32). In the first order communication the values, norms and metaphors are accepted as plausible. They have two important features: their core content is taken as self-evident and their guidance is not contested. People act on them and they accept from them direction, inspiration and guidance. In first order communication not the values, principles, etc. as such are at stake, but questions with regard to their applicability in certain practical situations.

'Second-order communication also is characterized by narration and argument, but the stories that are told and the arguments that are used, are intended to evoke discussion, to break through the boundaries, the walls, of the common life-world. Questions are not meant to elicit further clarification and enrichment or deeper understanding, but to call into question the traditional rules, values and norms' (Van der Ven 1999, 33v). Secondorder moral communication is about moral conflicts. Practices, norms or ideals that once were accepted are challenged now. In the food chain, second order communication is often started when generally accepted practices within the food chain are questioned and challenged by NGOs and when significant numbers of consumers endorse these questions by raising "consumer concerns".

The participants in moral communication - as non-strategic communication about values -need to direct this communication at: explicating one's own values and perspectives; understanding the other's values and perspectives; critical scrutiny of all values and perspectives; and searching for common values and perspectives.

In communication "strategic" and "non-strategic" are not necessarily mutual exclusive words. On the one hand it is clear that for moral communication actors (i.e. firms) have to go beyond the perspective of strategic and goal oriented behavior. On the other hand it is also clear that firms cannot fully abandon their strategic perspective; they need to survive in a competitive market. For moral communication in a market context it is therefore crucial to understand non-strategic communication as communicative interaction in which one does not directly aim at realizing one's goals, but in which one aims to understand the communication-partner. Reasons for engaging in such communication and reasons for expressing one's own identity (or opinion on particular issues like, for instance, GM 
crops) in such a communication might - and are often - strategic. For moral communication it is even better to be explicit about these reasons.

One might think that actors in the food chain - who operate in a competitive market are not able and willing to engage in non-strategic value communication. However, we have the impression that more and more companies accept that their role in the market transcends that of being a mere profit-maximizer or, to be more precise, that more and more companies accept that in order to survive in a market they cannot solely focus on profit in the market. More and more companies therefore explicitly accept some form of Corporate Social Responsibility (CSR).

However, for moral communication more is needed than the intention of doing so. With the development of communicative tools we aim at facilitating non-strategic communication about values between willing actors in the food chain (section 4). By describing the use and context of these tools (section 5) we hope to make clear under which circumstances these tools can be helpful for companies.

\section{The CoMoRe-kit}

The corporate moral responsibility (CoMoRe) kit is meant to help food corporations and their stakeholders to ascertain their moral position and responsibilities with respect to technological innovations in general and modern biotechnologies in particular. The focus of the CoMoRe-kit is to facilitate moral communication between corporations and their stakeholders (e.g. NGOs, stockholders, interest groups, consumers). The CoMoRe-kit is built on the idea that food chain value communication consists of three different dimensions that are usually intertwined with each other. The tools of the CoMoRe-kit thus refer to the following three dimensions of food chain value communication (see Box 1):

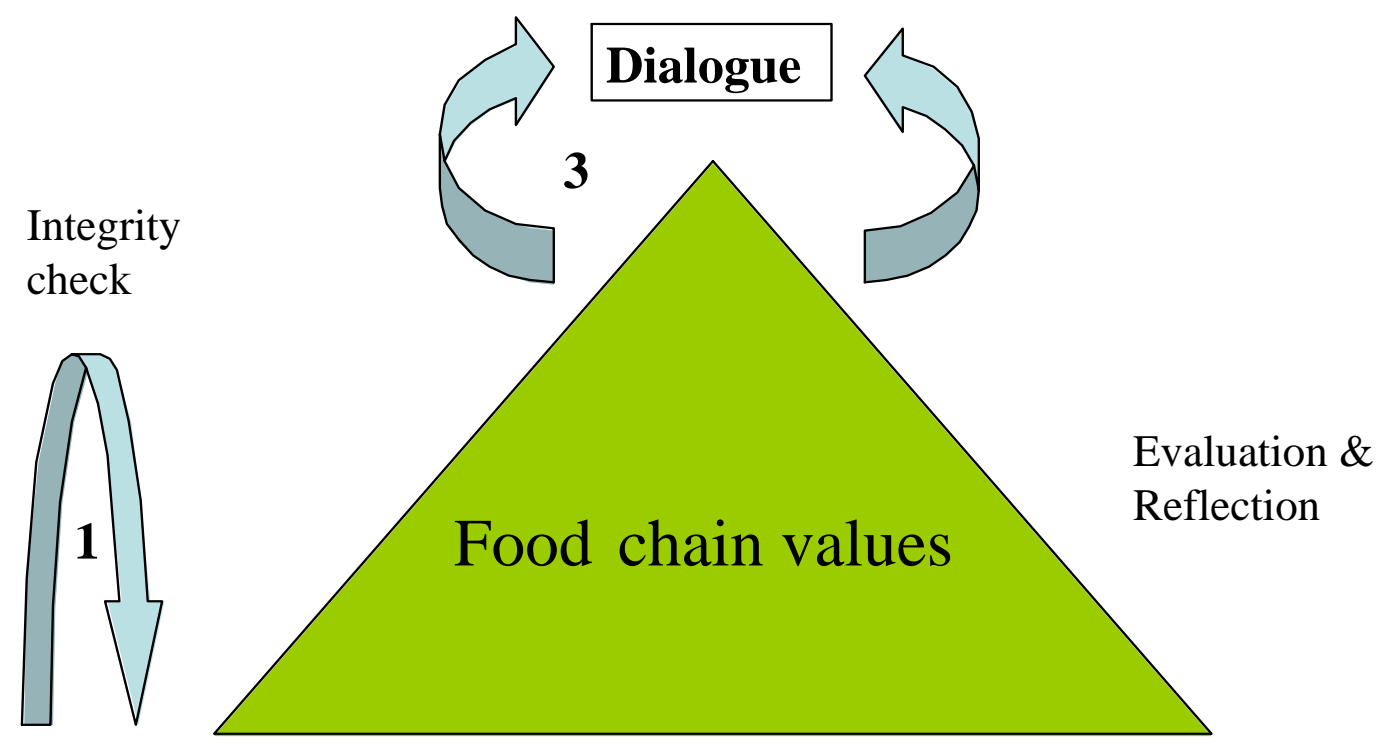

\section{Corporation}




\section{Box 1 The three dimensions of the CoMoRe-kit}

Clarifying corporate values (1)

What concerns, ethical values and identity does the corporation itself have, and how can these values and concerns be morally discussed in a profound manner? This clarification of the corporation's own values is the first dimension of food chain value communication and enables corporations to formulate their own moral positions and to make their routinised ethical decisions more explicit.

Clarifying stakeholder values (2)

What concerns and ethical values does a corporation ascribe to its stakeholders? This clarification of stakeholder values is the second dimension of food chain value communication and enables corporations to improve their understanding of the moral positions of others and the relative importance of the different stakeholders.

Stakeholder dialogue (3)

How can the moral values of the corporation and its stakeholders be communicated and debated, and how can actions and initiatives that comply with these values be assigned and taken up. This final dimension of food chain value communication enables corporations to distinguish between shared and challenged moral positions and to communicate about and cope with the differences in moral outlooks.

These three dimensions of food chain value communication include five phases and the CoMoRe-kit suggests using seven different ethical tools to go through these five phases (see Box 2): 


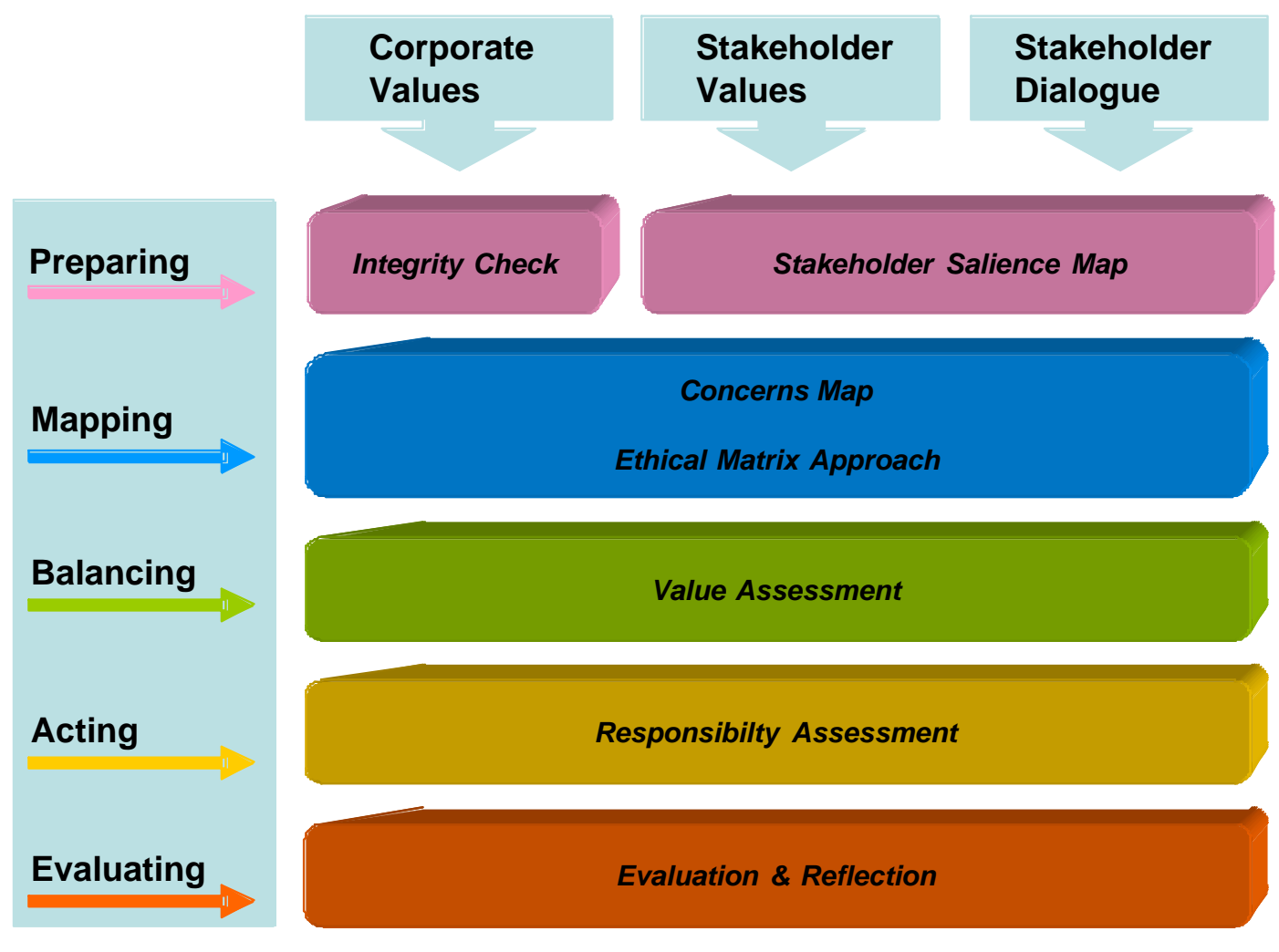

2 The five phases and seven tools of the CoMoRe-kit

Box

Integrity check (Preparing)

The use of an integrity check in the preparatory phase of clarifying corporate values ensures reflection with respect to the possibilities of open ethical debate within the corporation. It builds strongly on the business ethics approach of integrity audits. The check includes reflection on the organizational qualities (clarity, consistency, achievability, supportability, visibility, discussibility, and sanctionability) that determine the possibilities of open debate within the firm. It results in a clear view of potential corporate participants and of the organizational requirements regarding internal ethical deliberations (Kaptein, 1998; Kaptein \& Wempe, 2002).

\section{Stakeholder salience map (Preparing)}

The use of a stakeholder salience map in the preparatory phases of clarifying stakeholder values and stakeholder dialogues serves to gain insight in relevant stakeholders (now and in the future) on the basis of three stakeholder attributes: power, legitimacy, and urgency. It thus enables corporations to identify, characterize and prioritize relevant stakeholders (Mitchell et al., 1997).

\section{Concerns map (Mapping)}

The use of the concerns map in the mapping phases functions as a first acquaintance with the ethical reasons connected with certain concerns. It serves to gain insight into the main concerns of the corporation and/or its stakeholders. The map results in lists of relevant 
concerns and ethical reasons behind these concerns from the perspective of the corporation and/or its stakeholders (Beekman \& Van der Weele 2004).

Ethical matrix approach (Mapping)

The use of an ethical matrix approach in the mapping phases serves to find out more about different ways of reasoning. The approach is based on the principles of well-being, autonomy and justice. These principles represent the most important traditions in ethical theory and are used to translate concerns into corporate and/or stakeholder values and to illuminate the normative principles behind these values. The matrix results in an overview of important values considered from the perspective of the corporation and/or its stakeholders (Mepham 2005).

Value assessment (Balancing)

The use of value assessment in the balancing phases originally stems from the ethical method of value-tree analysis. It serves to deepen ethical deliberation in order to reach consensus on the most important ethical values regarding problematic issues and concerns. The method structures corporate and/or stakeholder values in a way that reflects the relations between various values and their relative importance or weight. It results in a hierarchical ordering of important values considered from the perspective of the corporation and/or its stakeholders.

The figure below illustrates the idea of a value tree. This (invented, still to complete and refine) value tree shows how various values are related towards each other. The figures indicate the relative weights of the values. The sum of the weights of values that are on the same level is always 1 . The relative weight of the value 'enough food' is, for instance, $0.14 \times 0.5=0.07$, while the relative weight of 'taste' is $0.12 \times 0.20=0.024$. Various techniques exist to define the weights. However, discussions regarding weights are perhaps more relevant than the final figures themselves, because they help to make explicit differences in appreciations and their underlying reasons or motivations. 


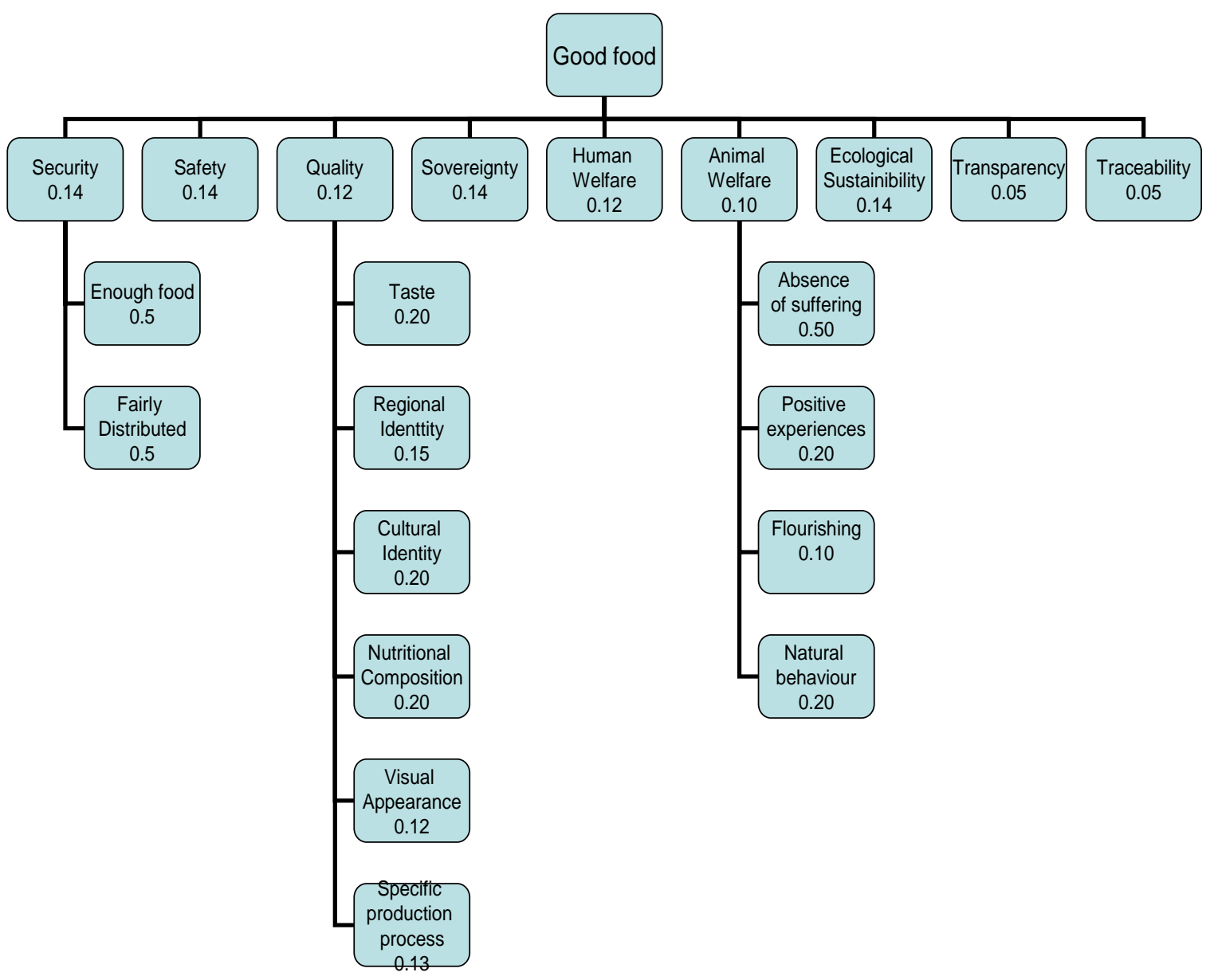

\section{Responsibility assessment (Acting)}

The use of responsibility assessment in the action phases also stems from value-tree analysis and serves to reach consensus on the actions and initiatives that are needed for the prioritized values. The method defines and assigns responsibilities and actions to the appropriate persons and/or organizations. It results in an overview of responsibilities and actions considered from the perspective of the corporation and/or its stakeholders.

\section{Evaluation \& reflection (Evaluating)}

The evaluation in the final phase ensures reflection with respect to the possibilities of open ethical debate with stakeholders. It includes a critical evaluation of and reflection upon all 'ethical activities' that have been done, especially with respect to the fair treatment of stakeholders. The evaluation results in insight into the level of integrity of the corporation with respect to the different interests of its stakeholders and in corporate awareness of the political, economic and cultural constraints in the context of corporate social responsibility. 


\section{Use and limits of the CoMoRe-kit}

If we can agree with the analysis of the actual situation of the agricultural and food sector as presented previously, what can then be the possible contribution of our toolkit? And what complementary initiatives should be taken in order to better attune the developments in this sector to commonly debated, morally founded, socially supported, but evertemporary interpretations of the guiding values?

\subsection{Use}

The analysis presented illustrates that the substantial topics we postulate in our toolkit as a starting point for debating concerns - food security, food quality, food safety, food sovereignty, human welfare (labor conditions), animal welfare, ecological sustainability (the environment) - are common topics with regard to the food system. What the analysis also illustrates is that we should be aware that these topics are mainly disciplined (in a Foucauldian vein), i.e. interpreted according to the prevailing discourse of industrialization and globalization. Corporate concentration in processing and distribution of food imposes specific 'universal' safety, quality and security criteria. Consequently, the products of small and/or more traditional farmers, suppliers and retailers, both at home and abroad, cannot easily comply ${ }^{6}$, food becomes even more insecure in developing countries, and many uncertainties pop up with regard to the environmental and health effects of such an industrializing and globalizing food system. It is still an open question whether the topic of food sovereignty can countervail the prevailing discourse.

What can be the contribution of the CoMoRe-kit? This toolkit aims at stimulating processes of clarifying corporate and stakeholder values and stakeholder dialogue. The nine concerns postulated from the very beginning thereby act as a normative framework against which a firm can weigh its own core activities. These processes are based on the involvement of various persons, either internal or external to the firm. This involvement is of a participatory kind: participants are expected to be autonomous actors, who bring their own perspectives into the various deliberations and who are prepared to question or defend them if necessary. This confrontation between various perspectives can contribute to the transparency of a firm, both towards itself and towards the outside world. This transparency can help firms to be explicit about their moral responsibilities, to adjust their actions and initiatives to their proclaimed moral identity and to explain to their direct and indirect stakeholders why they act as they do and which institutions - regulations, habits, customs, trends, traditions, organizational rules, and so on - prevent them to act as they themselves or their stakeholders would like to.

Systemization is necessary in order to prevent that one succeeds in defending any action. For that reason we deem the construction of a value tree an essential part of the CoMoRe-kit. It is always possible to find one or another ethical value with which to justify whatever action. Genuine ethical evaluation does, however, not so much depend on justification based on isolated values, but on justification based on a substantiated hierarchy of values.

The CoMoRe-kit can, to summarize, be seen as one of the mechanisms that can help enterprises in the agricultural and food sector to be accountable.

${ }^{6}$ The case of GM-food versus organic food in France could, however be considered as a -preliminary? counterexample. 


\subsection{Limits}

The worth of this mechanism of accountability is, of course, relative. It depends, to start with, on the persons that a corporation is prepared or can afford to involve in the respective clarification and communication processes. Is a firm's exercise of clarifying corporate values restricted to the persons at its head or does it also involve its employees, representatives of trade unions and of safety and environmental committees? Do the participants sufficiently represent the various cultural backgrounds of the different regional and national entities of a firm? Towards which stakeholders does a firm feel responsible: in the very first place towards its shareholders and only in the second place towards some of its suppliers and customers, or do dissident voices from marginalized groups of suppliers or customers also receive due attention? And which stakeholders does it consider or invite when engaging in the exercise of clarifying stakeholder values and in stakeholder dialogue?

The worth of our toolkit depends also on the extent of autonomy that the persons participating at the various exercises have or can afford. The extent of autonomy of a corporation's employees depends, for instance, on the formal structure and the informal culture of this firm. Are the formal structure and informal culture stimulating for open debates so that dilemmas and conflicts can be made explicit and explored? Serious doubts exist whether this can be the case within big transnational enterprises given present day concentration and the concomitant harsh struggle between them for maintaining and even enlarging their market share.

The extent of autonomy depends, in its turn, on the availability and digestibility of relevant information. Present-day food chains are often so long and the organization of the food system is so complex that it has become nearly impossible, even for persons with leading positions within important food companies, to get a good insight. This holds for the origins, production processes, safety and quality norms used to realize most of the food products that consumers buy in their supermarkets. It holds, perhaps even to a larger extent, for the evolving economic and governance structures of the food system that are heavily influencing and disciplining company choices and (national and international) debates and policies regarding food trade regulations.

\section{Stimulating initiatives}

We are convinced that the CoMoRe-kit should be complemented with other mechanisms. Corporate perspectives need to be confronted with and challenged by public initiatives. In the actual food system our ethical toolkit will not, taken on its own, induce fundamental discussions and be a driving force for morally substantiated thorough reforms. We consider our toolkit as a useful instrument to help firms respond to developments that are already going on in society. The CoMoRe-kit can help enterprises that are prepared to engage themselves into a public process of questioning present and defining future food production, processing and distribution practices. It can help them to respond to public criticisms and desires by defining, explaining and communicating their own position and by debating the responsibilities of both the enterprises themselves and of the other actors concerned (including the wider public). The CoMoRe-kit is surely not an appropriate instrument to put corporations, which are caught in struggles for market shares, on the track of open and honest moral communication. 
Confrontation of corporate perspectives with perspectives of the wider public implies, first, that opportunities should be created for the wider public to debate and substantiate their own perspectives. It is not reasonable to expect that such perspectives will emerge spontaneously. The wider public needs empowerment. Here lies an important responsibility for national and local public authorities, next to its continuing responsibility with regard to regulation of the food system (e.g., through competition regulation, definition and implementation of corporate liabilities). They should set up conditions for public spaces where people can voice, explore and check their concerns and expectations, based on their daily experiences and their personal histories. It is the particular task of non-governmental organizations - consumer, environmental, farmer organizations, and so on - to take care that the plain diversity of voices receives due attention, not only the politically correct - industrial, 'universal' - ones but also the marginal - local and traditional - ones.

Research shows that (European) citizens do attach value to the quality of life and livelihoods of (small) farmers, producers and retailers. Many citizens prefer to keep tradition, cultural heritage and regional identity alive in the way their food is produced, prepared and consumed. They, however, often need the comfort provided by supermarkets in order to succeed in the practical organization of their daily lives ${ }^{7}$. And citizen perspectives are, indeed, often at odds with prevailing consumer cultures of cheap food. Another task of NGOs is, hence, to provide these public spaces with relevant information concerning, e.g., the hidden costs of cheap food, the effects of industrial and global food processing and distribution on labor conditions, food security, the environment and social fabric, and the evolving power structures in the food system. According to Jacobsen et al., 'Consumers as strong economic players can shape markets, but only if they can make well-informed choices and if WTO labeling rules create an environment enabling both state and non-state actors to undertake appropriate consumer protection and information policies'. It is perhaps even more important to admit and to recognize publicly that the idea of 'well-informed choices' is an illusion, that our capacity to gain an overview of the relevant information is unavoidably limited, given the huge complexity of a globalizing food system. A globalizing food system means that most food chains encompass various countries with often different, lacking or failing quality and safety norms and control systems. Traceability and transparency are in such a context nearly 'missions impossible'.

Confrontation presupposes, second, that a common platform is created where corporate perspectives cannot only meet each other but also (scrutinized and empowered) public perspectives. The sense of such confrontation can be twofold. First, it can aim at mainstreaming industrializing and globalizing food systems, so that they comply better than before to the expectations of civil society and to cultural diversity with regard to its social, ecological and economic performance. Second, it can help to clarify the inherent limitations of the present-day globalizing and industrializing food system, especially with regard to the criteria of food sovereignty, transparency and traceability. And it can show why, which and to what extent alternative systems of producing, processing and distributing food are needed. It is important to stress that a common platform on which the various actors are present on an unequal footing (because of incomplete information, lack

\footnotetext{
7 See, for instance, La sécurité alimentaire: à quel prix?/Voedselveiligheid: tot welke prijs? and Présentation et analyse des résultats d'un dialogue/Presentatie en analyse van de resultaten van een dialoog tussen dertig Belgische burgers (http://www.kbsfrb.be/code/page.cfm?id_page=153\&ID=308, consulted on 08/09/05).
} 
of organization, and so on) can work counterproductive. It is not unconceivable that powerful companies consider a common platform as a way to adapt the expectations and organizational structures of their various stakeholders so that they match better with their own objectives and (international) organizational aspirations.

\section{Conclusion}

The CoMoRe-kit can be a valuable toolkit to help companies within the food chain to be accountable, i.e. to become aware of their own value system and to communicate it to other actors concerned. It can even support them to debate their normative choices and, thus challenged, to reconsider their responsibilities. We, however, assume that, in the actual food system, an ethical toolkit cannot, taken on its own, induce fundamental discussions and be a driving force for morally substantiated thorough reforms. In order to realize the tuning presently needed between technological and organizational choices within the food chain on the one hand and concerns and expectations of the wider public on the other hand, much more is needed. Well-organized public debates that allow citizens to form and substantiate their opinion are one important precondition. A common platform, where food chain companies can regularly meet the other actors concerned - an empowered citizenry, NGOs, public authorities - and where all actors can mutually and on an equal footing challenge choices and responsibilities, is probably another important trigger. 


\section{References}

Apotheker H. 2000. Is agriculture in need of ethics? J. Agric. Environ. Ethics 12(1)

Beekman V. 2000. You are what you eat: meat, novel protein foods \& consumptive freedom.” J. Agric. Environ. Ethics 12(2): 185.

Beekman, V. \& C. van der Weele (2004). Naar een gereedschapskist voor constructieve ethiek. (Towards a toolkit for a constructive ethics) Report nr. 7.04.10, Den Haag: LEI

Brom, F.W.A., B. Gremmen, T. Visak \& C. van der Weele, "Benchmarking”, in: V. Beekman (ed.), Description of Ethical Bio-Technology Assessment Tools for Agriculture and Food Production. Interim Report Ethical Bio-TA Tools (QLG6CT-2002-02594). LEI, The Hague 2004a, 43-67 (www.ethicaltools.info).

Brom, F.W.A., V. Beekman, R. de Graaff \& T. Visak, “Food chain communication”, in: V. Beekman (ed.), Evaluation of Ethical Bio-Technology Assessment Tools for Agriculture and Food Production. Interim Report Ethical Bio-TA Tools (QLG6CT-2002-02594). LEI, The Hague 2004b, 56-88 (www.ethicaltools.info).

Brom, F.W.A., E. de Bakker, M. Deblonde \& R. de Graaff, "Food chain value communication”, in: V. Beekman (ed.), Development of Ethical Bio-Technology Assessment Tools for Agriculture and Food Production. Interim Report Ethical Bio-TA Tools (QLG6-CT-2002-02594). LEI, The Hague 2005, 62-83 (www.ethicaltools.info).

Brom F.W.A. 2000. Food, consumer concerns and trust: food ethics for a globalizing market. J. Agric. Environ. Ethics 12(2):127.

Coleman, W.D. \& C. Chiasson (2002). State Power, Transformative Capacity and Adapting to Globalization: an Analysis of French Agricultural Policy, 1960-2000, Journal of European Public Policy, 9 (2)

Hegrenes, A. \& S.O. Borgen (2005). A Contractual Perspective on the Norwegian Agrifood Sector, Working Paper 2005 - 6, Centre for Food Policy \& Norwegian Agricultural Economics Research Institute, www.nilf.no/Publikasjoner/Notater/En/2005/N200506Hele.pdf, consulted on 06/09/05

IFAP (International Federation of Agricultural Producers) Statement on Legal and Institutional Aspects of Industrial Concentration in the Agri-Food sector, November 2004, www.ifap.org/en/publications/documents/legalaspectsconcentrationsENov04.pdf, consulted on $06 / 09 / 05$

IFAP, 'Industrial concentration in the agri-food sector' (sixth draft report), May 2002, (www.ifap.org/en/publications/documents/Concentrations6thdraftrevE.pdf, consulted on $02 / 09 / 05$

Jacobsen, M. (ICTSD - International Centre for Trade and Sustainable Development), A. Werth (ICTSD) \& B. Vorley (IIED - International Institute for Environment and 
Development) (2003). International Agricultural Reform and Power Balance in Agrifood Chains, Policy Views on Trade and Natural Resource Management www.iied.org/docs/trade/agrifood_chains.pdf, consulted on 02/09/05

Lang, T. (2003). Super(market)power! Current Tensions between Competition Policy and Food Policy. (Paper for Agri-Food Network seminar 24 September 2003)

MacMillan, T. (2005). Power in the Food System. Understanding trends and improving accountability. (Workshop series report of the Food Ethics Council) (www.foodethicscouncil.org, consulted 08/05).

McMichael, P. (2000). The Power of Food, Agriculture and Human Values, 17 (1), p. 2133.

Rapeepun Jaisaard (WTO), The Food Retailing Revolution: Experience from Poland http://www.eastagri.org/meetings/docs/meeting7/thefoo.ppt, consulted on 02/09/05

Staman J. and. F.W.A. Brom (2000). Proposal for a transatlantic platform for consumer concerns and international trade. J. Agric. Environ. Ethics 12(2): 207.

van der Ven, J.A. (1998). Formation of the Moral Self, William B. Eerdmans Publishing Company, Grand Rapids, Michigan/ Cambridge UK 